\title{
UPOTREBA SAVREMENIH SOFTVERSKIH REŠENJA U PRIPREMI I OBUCI ZA REAGOVANJE U VANREDNIM SITUACIJAMA
}

\author{
Miloš Milenković1, *, \\ Dalibor Kekić2, \\ Darko Glavaš \\ Dušan Marković ${ }^{4}$
}

\author{
'Ministarstvo unutrašnjih poslova - \\ Sektor za vanredne situacije, \\ Beograd, Srbija \\ ${ }^{2}$ Kriminalističko - policijski univerzitet, \\ Beograd, Srbija \\ ${ }^{3}$ Grad Beograd - Sekretarijat za poslove \\ odbrane, vanrednih situacija, komunikacije i \\ koordinaciju odnosa sa građanima, \\ Beograd, Srbija \\ ${ }^{4}$ Univerzitet Singidunum, \\ Beograd, Srbija
}

\begin{abstract}
Rezime:
Vanredne situacije, izazvane elementarnim nepogodama ili tehničko - tehnološkim nesrećama, sve su češća pojava, kako na lokalnom, tako i na globalnom nivou. Bilo koji oblik vanredne situacije sa sobom donosi i određene posledice u vidu ljudskih žrtava i materijalne štete. Pored toga, u većini situacija ostaju i posledice za čije je otklanjanje potreban duži vremenski period tokom faze asanacije i uspostavljanja uslova za život koji su bili aktuelni pre nego što je do vanredne situacije i došlo. U trenutnim uslovima, različiti oblici upravljanja nastoje da minimiziraju negativan uticaj vanrednih situacija izazvanih prirodnim ili ljudskim delovanjem. Jedan od načina jeste priprema i obuka subjekata i snaga koji su aktivno uključeni u pružanje odgovora, kao i stanovništva koje se nađe u opasnosti. Postoje različiti vidovi obuke, od onih koje uključuju višednevni progam i veliki broj učesnika, do individualnih modela namenjenih specifičnim korisnicima. Pored toga, uočena je potreba da se polaznicima obuke približe realne okolnosti u kojima se mogu naći u slučaju različitih rizika i opasnosti. Kao vrlo korisno sredstvo pokazala se upotreba savremenih softverskih rešenja u cilju simulacije vanrednih situacija. Kroz upotrebu različitih softvera polaznici obuke ili treninga mogu steći utisak kako izgleda kada se u realnosti dogodi, zemljotres, poplava, požar, hemijski akcident, ili neki drugi oblik elementarne nepogode ili tehničko - tehnološke nesreće. Aktuelno, u savremenim trening centrima čija je misija priprema stanovništva i operativnih snaga za reagovanje u vanrednim situacijama, sve više su u upotrebi savremena softverska rešenja koja simuliraju različite oblike vanrednih situacija i time pomažu u pripremi i obuci kako operativnih snaga, tako i različitih nivoa stanovništva.
\end{abstract}

Ključne reči:

vanredne situacije, obuka, simulacija, softverska rešenja.

\section{UVOD}

Savremeno društvo sve više se suočava sa posledicama vanrednih situacija izazvanih prirodnim ili tehničko - tehnološkim nesrećama. U oba slučaja, bez obzira da li se radi o posledicama delovanja prirode ili čoveka, nekada i minuti ili sekunde odlučuju da li će ljudi preživeti opasnost ili proći sa što manje gubitaka. U cilju minimiziranja posledica očekuje se da stanovništvo, kao i oni koji pružaju odgovor na vanredne situacije, budu što bolje pripremljeni na različite rizike. $U$ tom pravcu razvijaju se različiti modeli i tehnike koje se koriste u pripremi, odnosno u obuci.
Odgovorno lice:

Miloš Milenković

e-pošta:

milos10jul@gmail.com 
Institucije koje se bave pripremom i obukom za reagovanje u vanrednim situacijama, sve više pribegavaju upotrebi različitih softverskih rešenja u cilju približavanja realnosti krajnjim korisnicima. Kako postoji raznolikost vanrednih situacija, isto tako na tržištu egzistira i određen broj različitih programskih paketa koji se mogu upotrebiti u cilju simulacije elementarnih nepogoda i tehničko - tehnoloških nesreća. Tačnije, teško je kreirati jedno softversko rešenje koje se može koristiti prilikom obuke za reagovanje u slučaju zemljotresa, ili poplave i pojave klizišta, odrona i erozija. Veliki broj prednosti je uočljiv kada je reč o ovakvom načinu obuke. Naime, u oblasti upravljanja u vanrednim situacijama, pokazalo se mnogo korisnijim kada prolaznici obuke praktično prođu kroz ono što ih može očekivati u stvarnosti. Na taj način stiču mnogo bolji utisak o potencijalnim opasnostima i na kraju obuke budu pripremljeniji. Pored toga, trenutna praksa pokazuje da, bez obzira na isplativost, samo države sa višim standardima mogu izdvojiti novčana sredstva za nabavku softverskih rešenja sa pratećom opremom koji se koriste u simulaciji vanrednih situacija. U svakom slučaju, osnovni cilj rada je da prikaže najefikasnije programske pakete koji se trenutno koriste, kao i da ukaže na svrsishodnost ovakvog načina pripreme i obuke za reagovanje u vanrednim situacijama.

\section{PRIPREMA I OBUKA ZA REAGOVANJE U VANREDNIM SITUACIJAMA}

Koncept obuke primenjuje se u velikom broju sfera savremenog poslovanja i delovanja društva. Ako se kao primer uzmu multinacionalne kompanije, obuka i trening zaposlenih je jedan od primarnih ciljeva poslovanja. Naime, u okviru procesa upravljanja ljudskim resursima, i nakon regruatacije i selekcije, novozaposlenima je potrebno da se što pre adaptiraju i prilagode na novu radnu sredinu, kao i da ovladaju radnim procedurama u cilju postizanja tražene efikasnosti i efektivnosti.

Poput prethodno navedene pripreme, koncept obuke svoju primenu nalazi i u drugim sferama rada i funkcionisanja društva. Jedna od sfera gde je koncept obuke sve više u primeni je upravljanje u vanrednim situacijama. Pre nego što se krene u detaljnije objašnjenje primene obuke u ovoj oblasti, neophodno je ukratko definisati šta to predstavlja vanrednu situaciju. Naime, evidentno je da se ovaj termin sve više upotrebljava, ali da postoje terminološke zabune. Za potrebe ovog rada iskoristiće se definicija vanredne situacije u skladu sa novim zakonskim rešenjem u Republici Srbiji koji definiše oblast smanjenja rizika od katastrofa i upravljanja vanrednim situacijama. Vanredna situacija je stanje koje nastaje proglašenjem od nadležnog organa kada su rizici i pretnje ili nastale posledice po stanovništvo, životnu sredinu i materijalna i kulturna dobra takvog obima i intenziteta da njihov nastanak ili posledice nije moguće sprečiti ili otkloniti redovnim delovanjem nadležnih organa i službi, zbog čega je za njihovo ublažavanje i otklanjanje neophodno upotrebiti posebne mere, snage i sredstva uz pojačan režim rada [1]. Drugim rečima, o vanrednoj situaciji se može govoriti samo kada su obim i posledice takve da prevazilaze redovno delovanje hitnih službi sa značajnim posledicama po život i zdravlje ljudi, kao i materijalna i kulturna dobra. U takvim uslovima od izuzetnog značaja je imati pripremljeno i obučeno stanovništvo, kao i operativne snage. Tačnije, mora se imati razvijen sistem obuke različitih kategorija koje mogu biti obuhvaćene rizicima i pretnjama od elementarnih nepogoda i tehničko - tehnoloških nesreća. $\mathrm{U}$ praksi, obuku i trening za reagovanje u vanrednim situacijama sprovode nacionalne institucije koje se organizaciono posmatrano deo ministarstava, direkcija ili drugih vladinih tela u čijoj je nadležnosti oblast upravljanja vanrednim situacijama. Najčešće su to trening centri osnovani na nacionalnom nivou, dok u nekim državama postoje primeri i regionalno osnovanih trening centara. Teorijski posmatrano, ključni faktor za uspešno obrazovanje i obuku u oblasti upravljanja vanrednim situacijama je formalno obrazovanje. To znači implementaciju nekih tema u školama, kako u osnovnim, tako in a nivou srednjeg obrazovanja. Postoji nekoliko opcija kako sprovesti ovu vrstu obrazovanja u školama. Formalno obrazovanje se odnosi na obrazovanje u institucijama (uglavnom školama) kroz institucionalizovani sadržaj nastavnih planova i programa [2]. Sa druge strane, obuka u oblasti upravljanja vanrednim situacijama treba da koristi prvenstveno neke metode neformalnog obrazovanja. Najčešće korišćene metode su: treninzi, aktivnosti podizanja svesti, publikacije, radionice i seminari, demonstracije, izložbe i simulacije, igre (u prethodnom periodu dostupne na internetu), obrazovanje kroz volonterske aktivnosti, i slično [3]. Kako je navedeno, simulacije predstavljaju jedan od načina obuke koja se koristi u delu nefomralnog obrazovanja i obuke za reagovanje u vanrednim situacijama. Naime, ova metoda se na vrlo kompleksan način može implementirati u okvirima formalnog obrazovanja. Sa druge strane, vrlo je korisno primenjivati metodu simulacije kada je reč o obukama u trening centrima i to pogotovo kada su u pitanje operativne snage, odnosno stanovništvo koje se ciljano priprema i obučva za reagovanje u vanrednim situacijama. Prema Ivancevich-u (1998) i Dessler-u 
(2007), u osnovi, postoje četiri moguća pristupa obuci, od kojih je jedna upravo pripremna simulaciona obuka. Prema ovima autorima naglašava se da pripremna simulaciona obuka - je takva obuka gde oni koji učestvuju u ovom vidu obuke, stiču znanja i veštine u okruženju koje simulira realno radno okruženje što god je moguće više. Ova procedura je dosta skupa. Zaposleni koji su obučavani na ovaj način imaju, u određenom procentu, problem u prilagođavanju realnoj radnoj sredini koja je više stresna i manje bezbedna [4]. Kako se vidi u definiciji, ovakav vid obuke je izuzetno skup, a jedan od razloga je što se moraju koristite nastavna sredstva i oprema, poput savremenih softverskih rešenja, koja zahtevaju izdvajanje značajnih finansijskih sredstava. Takva situacija je i sa primenom metode simulacije upotrebom progamskih paketa u pripremi i obuci za reagovanje u vanrednim situacijama. Potrebno je dosta vremena i uloženih finansijskih sredstava kako bi se razvio jedan softver koji simulira opasnost od zemljotresa i poplava. Sa druge strane, velike su prednosti kada se koriste informaciono - komunikacione tehnologije prilikom simuliranja vanrednih situacija izazvanih različitim elementarnim nepogodama ili tehničko - tehnološkim nesrećama. Sigurno da je jedna od najvećih prednosti ta što se polaznici obuke dovode u realno okruženje, upravo onakvo kakvo ih očekuje u realnim uslovima kada dođe do vanredne situacije.

\section{SAVREMENA SOFTVERSKA REŠENJA KOJA SE KORISTE U SIMULACIJAMA VANREDNIH SITUACIJA}

Trenutno, nekoliko renomiranih svetskih proizvođača softvera radi na razvoju i izradi programskih paketa koji su mogu koristiti u svrhe obuke i sumulacije vanrednih situacija.

Jedan od primera je zajednička saradnja rumunske kompanije Deltamed i i holandskog konzorcijuma. Naime, rumunska kompanija izrađuje specijalizovana vozila sa posebnom opremom u koja se ugrađuju softverska rešenja za simulacije vanrednih situacija izrađena od strane holandskog konzorcijuma. Kompanija Deltamed je specijalizovani proizvođač vozila koja se koriste u radu hitnih službi. Upravo, jedan od tipova vozila predstavlja kamion koji je opremljen posebnim softverom koji proizvodi holandski konzorcijum i koji se koristi u obuci različitih kategorija koji mogu biti pogođeni vanrednim situacijama ili reagovati u svojstvu operativnih snaga.

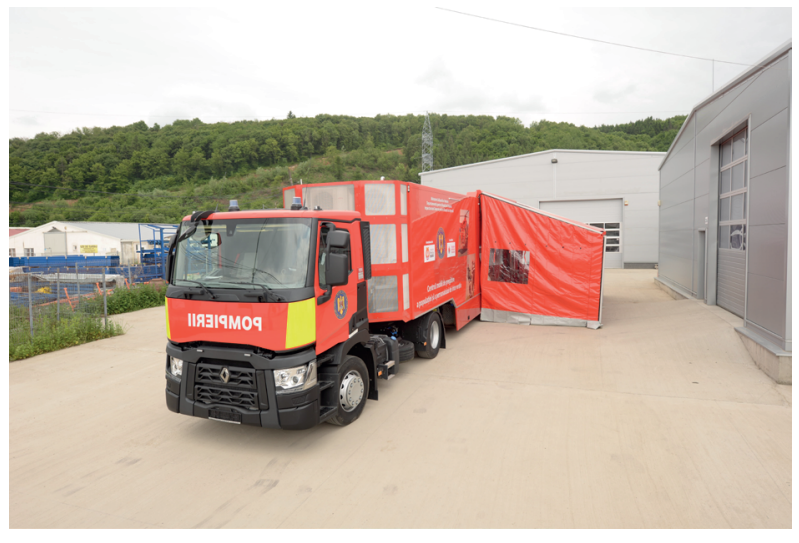

Slika 1. Izgled kamiona koji je opremljen softverom za simulaciju vanrednih situacija [5]

Prednost ovakvog načina realizacije obuke je prevashodno mobilnost. Treninzi i obuke se mogu realizovati na različitim lokacijama. U skladu sa potrebama, obuka ili trening se može organizovati na izdvojenim područjima i ne zavisi od raspoloživosti jednog objekta. Neke od najvažnijih karakteristika softvera koji se koristi u ovakvom načinu obuke su:

- Uključenost različitih scenarija - Softver omogućava da se razradi bilo koji oblik opasnosti, od manjih vanrednih događaja do vanrednih situacija sa ozbiljnijim posledicama,

- Realističnost u primeni - Učesnici obuke uz korišćenje softvera imaju tendenciju da doživljavaju incident kao veoma realističan. Stres i napetost tokom vežbi su prilično ozbiljni, jer su dileme i problemi koji se pojavljuju usko slični stvarnom životu. Učesnici dobijaju trenutne povratne informacije od posledica njihovih odluka,

- Traženje i prepoznavanje vizuelnih znakova Softversko rešenje omogućava učesnicima da vežbaju prepoznavanje vizuelnih znakova i opasnosti.

- Neograničeno vežbanje bez obzira na lokaciju Scenariji incidenata nude mogućnost obuke kad god i gde god to žele krajnji korisnici. Jednom kada se kreira softver, pruža se mogućnost da se koristi na različitim lokacijama. Ovo je naročito izraženo u kombinaciji sa vozilom koje proizvodi rumunska kompanija Deltamed.

- Procena opasnosti i komunikacija - Polaznici obuke vide scenario da bi imali uvid u celokupnu situaciju. Tokom timske obuke polaznici mogu koristiti različita sredstva komunikacije. Sa druge 
strane, instruktori su virtualno osoblje koje prati rad polaznika i iz kontrolne sobe može zadavati dodatna pitanja i sugestije.

- Komandovanje i kontrola tokom obuke - Polaznici su tokom cele obuke kontrolisani preko softvera od strane instruktora. Instruktor ima potpunu kontrolu i uvid u pružena rešenja i odgovore, odnosno predloge upotrebe različitih materijalno - tehničkih i ljudskih resursa. Instruktor ima mogućnost da menja scenario kako bi stekao uvid da li se polaznici mogu prilagoditi novim uslovima i donositi adekvatne odluke. Pored toga, ovakav vid softverskog rešenja pruža i mogućnost da se tokom timske obuke polaznicima omogući i redovna koordinacija ,licem u lice" kroz sastanke u virtuelnom okruženju, organizovanje video konferencija i u cilju planiranja narednih akcija reagovanja.

- Evaluacija i povratne informacije - Nakon obuke instruktor pregleda radnje, aktivnosti i odluke sa polaznikom obuke. Instruktor, zahvaljujući ovom softverskom rešenju, može da se u svakom trenutku vrati nazad kroz scenario i da se na taj način sagleda konkretna situacija. [6]

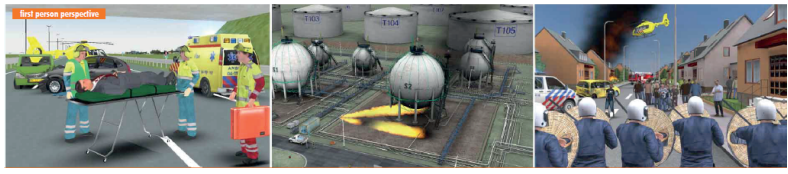

Slika 2. Izvod iz jedne od obuka i upotrebe softverskog rešenja[6]

Sledeći primer softvera koji se koristi u simulaciji vanrednih situacija i u obuci jeste proizvod kompanije C4i. C4i je američka kompanija u privatnom vlasništvu čija je vizija da učini svet sigurnim kroz obuku i tehnologiju. Stručne oblasti koje pokriva ova komapnija uključuju najsavremenije simulacije i softverska rešenja za obuku i razvoj, a sve na osnovu prilagođenog softvera. Jedan od softvera koji je ova kompanija razvila za potrebe obuke za reagovanje u vanrednim situacijama jeste EDMSIM. EDMSIM je interaktivno, softversko rešenje za obuku za vanredne situacije. Softversko rešenje je posebno dizajnirano za operativne snage koje se aktiviraju u slučaju vanrednih situacija, kao i za operativne centre i civilno rukovodstvo. Softver je vrlo fleksibilan i prilagodljiv alat. EDMSIM omogućava timovima koji učestvuju u obuci da poboljšaju komunikaciju, provere planove i procedure za vanredne situacije, odnosno da bolje funkcionišu u okruženju koje realno prikazuje okruženje pogođeno elementarnom nepogodom ili tehničko - tehnološkom nesrećom [7].

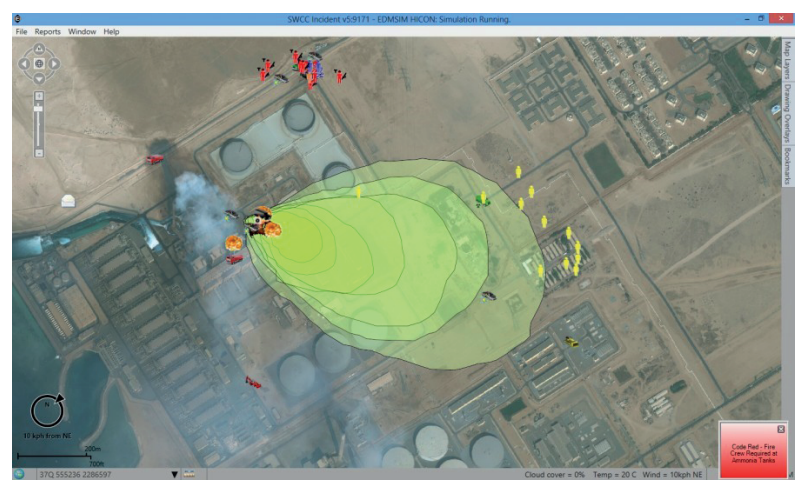

Slika 3. EDMSIM - praktičns upotreba softverskog rešenja[7]

EDMSIM koriste različiti subjekti, poput US Northern Command, Vojska i Nacionalna garda SAD, NATO i mnogi drugi. Jedna od glavnih karakteristika EDMSIM skalabilnost. To podrazumeva da se obuka upotrebom ovog softverskog rešenja može koristiti na lokalnom, regionalnom i najvišem nacionalnom nivou, kako u odvojenom režimu, tako i istovremeno. Na taj način pružaju se dodatne mogućnosti da različiti nivoi upravljanja i odlučivanja istovremeno se obučavaju i provežbavaju procedure i pružanje odgovora u slučaju vanredne situacije. Jedan od bitnih dokumenta koji se koristi u svim fazama upravljanja u vanrednim situacijama jeste plan zaštite i spasavanja. EDMSIM pruža opciju da se sam plan implementira u okviru raličitih softverskih pozicija i da se nakon toga utvrdi kako polaznici obuke, koji su ujedno i krajnji korisnici plana, primenjuju plan u realnim uslovima. Operativnom osoblju koje učestvuje u obuci putem softvera EDMSIM na raspolaganje se stavljaju isti oni ljudi i materijalno - tehnički resursi koje bi na osnovu plana koristili i u realnim uslovima. U takvom vidu obuke softver stavlja i određena ograničenja. Na primer, planom je predviđeno da će se u slučaju poplave u zaštiti i spasavanju ugroženih građana koristiti tri specijalistička tima sa po 5 spasioca i da svaki tim ima čamac sa odgovoarajućom opremom. Ako polaznici obuke u rešavanju zadataka na osnovu predefinisanog scenarija, donesu odluku o angažovanju većeg broja spasilaca i opreme u odnosu na predviđene parametre planom, softver će izdati 
upozorenje da odabrani resursi nisu na raspolaganju. $\mathrm{Na}$ osnovu toga, omogućeno je tokom obuke da polaznici prođu i kroz upravljanje resursima. Pre početka obuke, u softver EDMSIM se implementira jedan vid baze podataka koja sadrži sve informacije o dostupnim ljudskim i materijalno - tehničkim resursima koji su dostupni na osnovu teritorije obuhvaćene scenarijom. Jedna od prednosti upotrebe ovakvog softvera je što je veoma jednostavan za upotrebu. Grafička rešenja i način korišćenja su prilagođeni osobama za osnovnim nivoom znanja korišćenja kompjutera. Kao i prethodno opisano softversko rešenje, i EDMSIM omogućava evaluaciju nakon obuke, analizu urađenog i preporuke za poboljšanje rada u realnim uslovima.

Prethodna dva primera upotrebe softverskih rešenja su samo neki od raznolikog broja koji se trenutno nudi na tržištu. Ipak, za potrebe ovog rada uzeti su kao reprezentativni primeri s obzirom na činjenicu široke upotrebe i pozitivnih komentara polaznika obuke koji se se na ovaj način pripremali za reagovanje u vanrednim situacijama ili u svojstvu civila, ili kao pripadnici profesionalnih i operativnih jedinica.

\section{PREDNOSTI I NEDOSTACI UPOTREBE SAVREMENIH SOFTVERSKIH REŠENJA U PRIPREMI I OBUCI ZA REAGOVANJE U VANREDNIM SITUACIJAMA}

Kao i u većini drugih slučajeva, upotreba savremene tehnologije i programskih rešenja sa sobom nosi niz prednosti, kao i nedostataka. Slična je situacija i sa upotrebom savremenih softverskih rešenja u pripremi i obuci za reagovanje u vanrednim situacijama.

Sigurno da je najveća prednost što se kroz ovakav vid obuke polaznici dovode u približno realne situacije onima koje ih mogu očekivati u stvarnim uslovima kada dođe do vanredne situacije izazvane elementatnim nepogodama ili tehničko - tehnološkim rešenjima. Sa aspekta krajnjih korisnika u ovoj oblasti, od izuzetnog je značaja da se stekne utisak šta svaka od opasnosti može izazvati. Na primer, nije isto kada se realizuje obuka za reagovanje u slučaju poplava ili šumskih požara. Drugačija je taktika reagovanja, upotrebe opreme, načina evakuacije ugroženih lica i drugo. U skladu sa time, softverska rešenja pružaju mogućnosti impelemntacije različitih scenarija koja su prilagodljiva realnosti. Na taj način, ako dođe do iste ili slične situacije, unapred će biti pripremljeniji, s obzirom da su upotrebom softvera već prošli kroz proces donošenja odluka i upotrebe različitih materijalno - tehničkih sredstava. Dalje, na primeru prvog načina obuke koji je predstavljen u prethodnom poglavlju, izražena je još jedna prednost, a to je mobilnost u obuci. Naime, kombinacijom upotrebe softverskog rešenja u vozilu, omogućeno je da se obuka realizuje na različitoj teritoriji u skladu sa potrebom. Takođe, time se ostvaruju i značajne uštede i polaznici obuke ne moraju napuštati svoju radnu sredinu i dolaziti u trening centre koji su u većini situaciji geografski dislocirani. Dalje, prikazana softverska rešenja predstavlaju vrlo jednostavne platforme za krajnje korisnike. Nije potrebna dodatna obuka kako bi se polaznici pripremili. Kako je i naglašeno, od polaznika se očekuje osnovni nivo znanja o upotrebi informaciono - komunikacionih tehnologija.

To predstavlja značajnu prednost. Savremena obuka se ne može zamisliti bez dela koji se odnosi na evaluaciju. Naime, osobe koje prolaze kroz obuku, moraju na kraju dobiti neki vid izveštaja o svom radu koji bi sadržao i preporuke za dalji rad i unapređenje kompetencija. Upotreba softverskih rešenja u pripremi i obuci za reagovanje u vanrednim situacijama pruža i tu mogućnost. Tokom obuke, automatski se memorišu pružena rešenja i odgovori na različite zadatke i scenarija. Kada se završi obuka, instruktori mogu na vrlo jednostavan i lak način pregledati odgovore poalznika obuke i time izvršiti evaluaciju. Na kraju, prednost koju donosi ovakav vid obuke u oblasti vanrednih situacija jeste i mogućnost učenja na daljinu. Uz upotrebu internet tehnologija, omogućeno je da istovremeno u obuci učestvuju polaznici iz različitih krajeva što doprinosi i jačanju međunarodne saradnje u oblasti upravljanja u vanrednim situacijama.

Jedan od glavnih nedostataka koji se pojavljuje prilikom korišćenja savremenih softverskih rešenja u pripremi i obuci za reagovanje u vanrednim situacijama jeste finansijski aspekt. Naime, potrebno je izdvojiti značajna finansijska sredstva kako bi se softver kupio, dalje koristio i održavao. Na taj način, sužava se broj država i njihovih trening centara koji mogu sprovoditi odbuku upotrebom savremenih softverskih rešenja. Takođe, pokazalo se neisplativim i da države svoje predstavnike operativnih snaga upućuju u inostranstvo na obuku ucentre koji poseduju navedenu opremu. $U$ vezi sa prethodnim, javlja se i sledeći nedostatak, a to je održavanje softvera. Prilikom nabavke softverskog rešenja definiše se i način na koji će se vršiti dalje održavanje, odnosno kako će se vršiti eventualne popravke u slučaju kvara. Postoji nekoliko mogućnosti, od dolazaka predstavnika kompanije koja je prodala softver da direktno reše problem, do daljinksih popravki putem posebnih aplikacija. U svakom slučaju, to predstavlja dodatni trošak koji 
može odgovoriti nadležne institucije da sprovode obuku i pripremu za reagovanje u vanrednim situacijama putem savremenih softverskih rešenja.

\section{ZAKLJUČAK}

Savremene tendecije i posledice koje prouzrokuju vanredne tendencije izazvane elementarnim nepogodama i tehničko - tehnološkim nesrećama ukazuju na neophodnost da se i stanovništvo i operativne spasilačke snage što bolje pripreme i obuče.

U tom pravcu stvaranje realnih uslova u kojima se mogu naći tokom vanredne situacije, predstavlja jedan od primarnih ciljeva tokom obuke. Tako se i došlo na ideju da se tokom obuke koriste savremena softverska rešenja koja simuliraju različite rizike i opasnosti koje prouzrokuju vanredne situacije, kao što su zemljotresi, poplave, šumski požari, hemijski akcidenti i drugo.

Trenutno je aktuelno nekoliko softverskih paketa koji se mogu koristiti u ove svrhe. Izrađeni su od strane renomiranih svetksih kompanija koje posluju u oblasti informaciono - kmunikacionih tehnologija. Nadležne institucije za obuku na nacionalnom nivou time dobijaju mogućnost kupovine i dalje upotrebe programskih paketa koje mogu pomoći u pripremi kako stanovništva, tako i operativnih snaga, za što efikasnije reagovanje ukoliko dođe do vanredne situacije.

Kako je u radu naglašeno, prisutne su i prednosti i nedostaci ovakvog vida obuke. Takođe, više je pozitivnih stana primene savremenih softverskih rešenja u obuci za reagovanje u vanrednim situacijama. Međutim, izraženi nedostatak se ogleda u značajnim finanijskim sredstvima koja je potrebno izdvojiti za nabavku, upotrebu i dalje održavanje ovih softvera. Međutim, ako se ima u vidu do koji posledica dolazi nakon određenih vanrednih situacija, tačnije koliko je finansijskih sredstava potrebno da bi vratili uslovi života i boravka koji su bili i ranije, evidentna je isplativost realizacije ovakvog načina obuke za reagovanje u vanrednim situacijama.

\section{LITERATURA}

[1] “Sl. glasnik RS”, br. 87/2018. Zakon o smanjenju rizika od katastrofa $i$ upravljanju vanrednim situacijama Preuzeto Mart 01, 2019, sa https://www. paragraf.rs/propisi/zakon-o-smanjenju-rizika-odkatastrofa-i-upravljanju-vanrednim-situacijama. html

[2] Komac, B., Ciglič. R., Erhartič. B., Gašperič, P., Kozina, J., Orožen Adamič, M., Pavšek, M., Pipan, P., Volk, M \& Zorn, M., (2010). Risk Education and Natural Hazards CapHaz-Net WP6 Report. AntonMelik Geographical Institute of the Scientific Research Centre of the Slovenian Academy of Sciences and Arts. Ljubljana, p.6

[3] Building Research Institute (BRI) and National Graduate Institute for Policy Studies (GRIPS). (2007). Project Disaster Education. Japan. p.4.

[4] mr Ivanković, V., (2016). Metode izvođenja obuke $i$ razvoja. Centar za razvoj ljudskih resursa i mendžment MNG Centar doo

[5] Deltamed. (2018). Product broschure. Preuzeto Mart 07, 2019, sa http://www.deltamed.ro

[6] E-Semble. (2012). XVR brochure. Preuzeto Mart 09, 2019, sa https://www.futureshield.com/img/ brochures/XVR-Brochure-UK.pdf

[7] C4i. (2018) EDMSIMbroschure. Preuzeto Mart 09, 2019, sa http://www.c4itrgtech.com/products/edm$\operatorname{sim} /$ 